Copyright (C) 2014 by Academic Publishing House Researcher

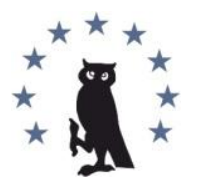

Published in the Russian Federation

European Researcher

Has been issued since 2010.

ISSN 2219-8229

E-ISSN 2224-0136

Vol. 85, No. 10-2, pp. 1816-1827, 2014

DOI: 10.13187/er.2014.85.1816

www.erjournal.ru

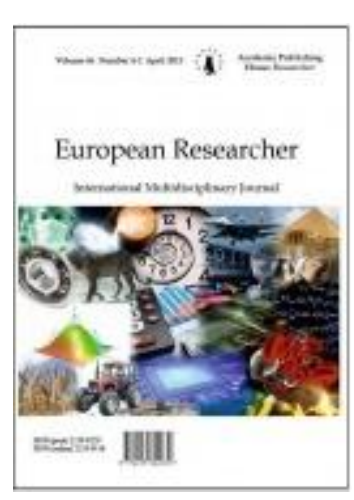

Engineering sciences

Технические науки

UDC 04

\title{
Formalization of the Problems of Marketing in Managing the Implementation of Industrial Innovation Projects
}

${ }^{1}$ Aleksandr Kalikh

${ }^{2}$ Leonid Mylnikov

\author{
${ }^{1}$ Perm National Research Polytechnic University, Russian Federation \\ Komsomolskiy prospect 29, Perm, 614990 \\ Master \\ E-mail: kalikh@bk.ru \\ ${ }^{2}$ Perm National Research Polytechnic University, Russian Federation \\ Komsomolskiy prospect 29, Perm, 614990 \\ Dr. (Technic), Associated Professor \\ E-mail: leonid@pstu.ru
}

\section{Abstract}

The article, basing on statistical datas from Data Mining Cup (www.dataminingcup.de) and described the algotithm for data analysis of coinnovation projects. This algorithm can help to find a decision for modernisation of products groups' production and plane future modernisation of manufacture adapted for product lines.

Keywords: management; innovation; project; levels of management; on-line store; market; Naive Bayes algoryth.

\section{Introduction}

During the last decades we have seen the establishment of a new scientific discipline management of innovation projects - part of the theory of socio-economic systems, in which methods, forms, and ways of the most effective and efficient management of innovation are being studied.

At this point you can not give a precise definition of the discipline. In essence - it is a complex of interrelated activities aimed at achieving the goals within a specified period of time and under budget established during test and refine the idea of creating a new product, including a forecast of its market appeal.

The most common purpose of the innovative project is to obtain confirmation of the technical, technological and commercial options for further planning of the business, ie 
justification of the business plan of the investment project of production, sales and after sales service of the developed product [8].

The concept of "innovation project" is used in several ways:

- as a business, activity, event, suggesting a complex implementation of any actions that achieve certain goals;

- as a system of organizational-legal and settlement of financial documents required for the implementation of any action;

- the process of innovation.

In general, the innovative project is a complex system of measures, interdependent and interconnected by resources, time, and by performers and aimed at achieving specific goals.

Each innovative project, depending on the tasks can be classified differently (Fig. 1).

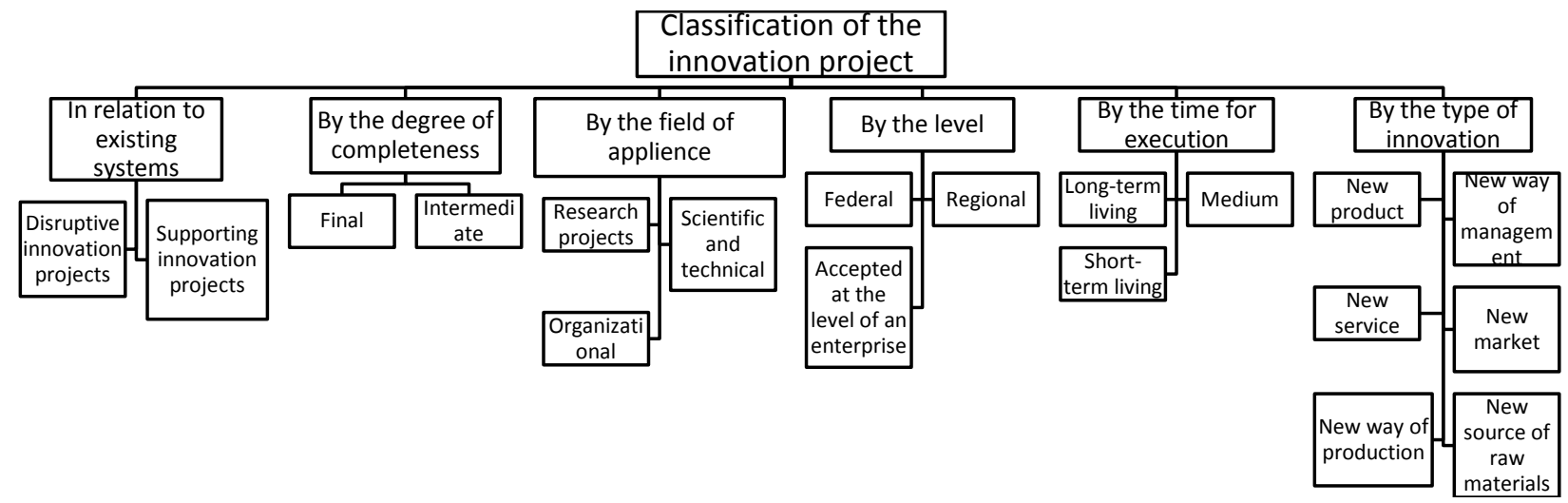

Fig. 1. An estimated classification of innovative projects

It is important to identify the most characteristic features of the innovation project:

1. Each innovation project goes through the cycle "science-production-consumption". The idea of the innovative project is based on scientific research and marketing, as well as production in the market adjusts to the consumer and relies on modern technology.

2. The difficulty of predicting outcomes, and as a result - increased risks. The emergence of the new is always associated with multiple risks (public - rejection process; technological underdeveloped industrial base, niche - the immaturity of the market, etc.).

3. The development and implementation of innovative projects is a creative and unique challenge. That is why much depends on the enthusiasm and personal interest of performers, on the organization of the project participants. The presence of free will and high motivation of participants of the project makes the usual organization of labor and the creation of labor discipline inappropriate. Therefore, we need an adequate approach to selecting managers' management style.

4. The absence of the usual standards for the innovative project. Even the most clear-cut concept of the project may undergo major changes during development.

An innovative project has different ways of describing and urgent objectives depending on stage at which it considered to be, and the level of management (Fig. 2).

Fig. 2. clearly shows that every innovative project throughout its life goes through several major phases. The first few steps can be considered together as a phase of establishment of the project. In addition, at each stage it has its own problems, formulation and correct solution of which is an important factor of success of the project. If to consider the product innovations according to the ISO classification, products can be divided on the following life cycle stages that will have its own specific characteristics [9]: 
1. The formation of an innovative idea (the concept).

On the one hand, the innovative idea is the basis of innovative projects that is reflected in the formulation of a general (ultimate) goal of the project; on the other hand, by the formation of an innovative idea a conceived plan of actions is considered, ie, methods or ways of achieving the project objectives.

Simultaneously with the formation of innovative idea of the project, market researches is being held in order to:

- to analyze the possibilities and economic feasibility of replacing the products with new types of target products;

- set of possible consumers of the target product of the project;

- examine the structure of industries, providing the project with raw materials, energy, components, etc.;

- to analyze the economic and social impacts of the project.

2. Development of the project.

It is a process of finding solutions to achieve the ultimate goal of the project and the formation of interconnected by time, resources, and performers complex of tasks and actions to implement the project. At this stage, a comparative analysis of different options for achieving the objectives of the project is being held and the most viable project for implementation is being selected. In the development of any project it is important to take into account such properties as competitiveness, economic and strategic validity, legal protection of the project, cause the further viability of the project is being estimated by this factors (Fig. 3).

Then, the plan for an innovative project implementation is being developed, the problems of a special organization for the work on the project are being solved, a competitive selection of potential performers of the project is being held and contract documentation is being issued.

3. Implementation of the project.

It is a process of implementing the goals of the project. At this stage the control of schedules executing, resource consumption, the adjustment of arising deviations and operational control of the implementation of the project are being held.

4. Completion of the project.

This is the process of commissioning of project results to the customer and of closing of contracts (agreements). It is a complete stage of the life cycle of the innovation project

5. Warranty and after sales service.

It is evident that the development and management of innovative project is a quite voluminous and multi-faceted set of tasks, only the successful solution of which in each stage leads to a successful implementation of the project. 


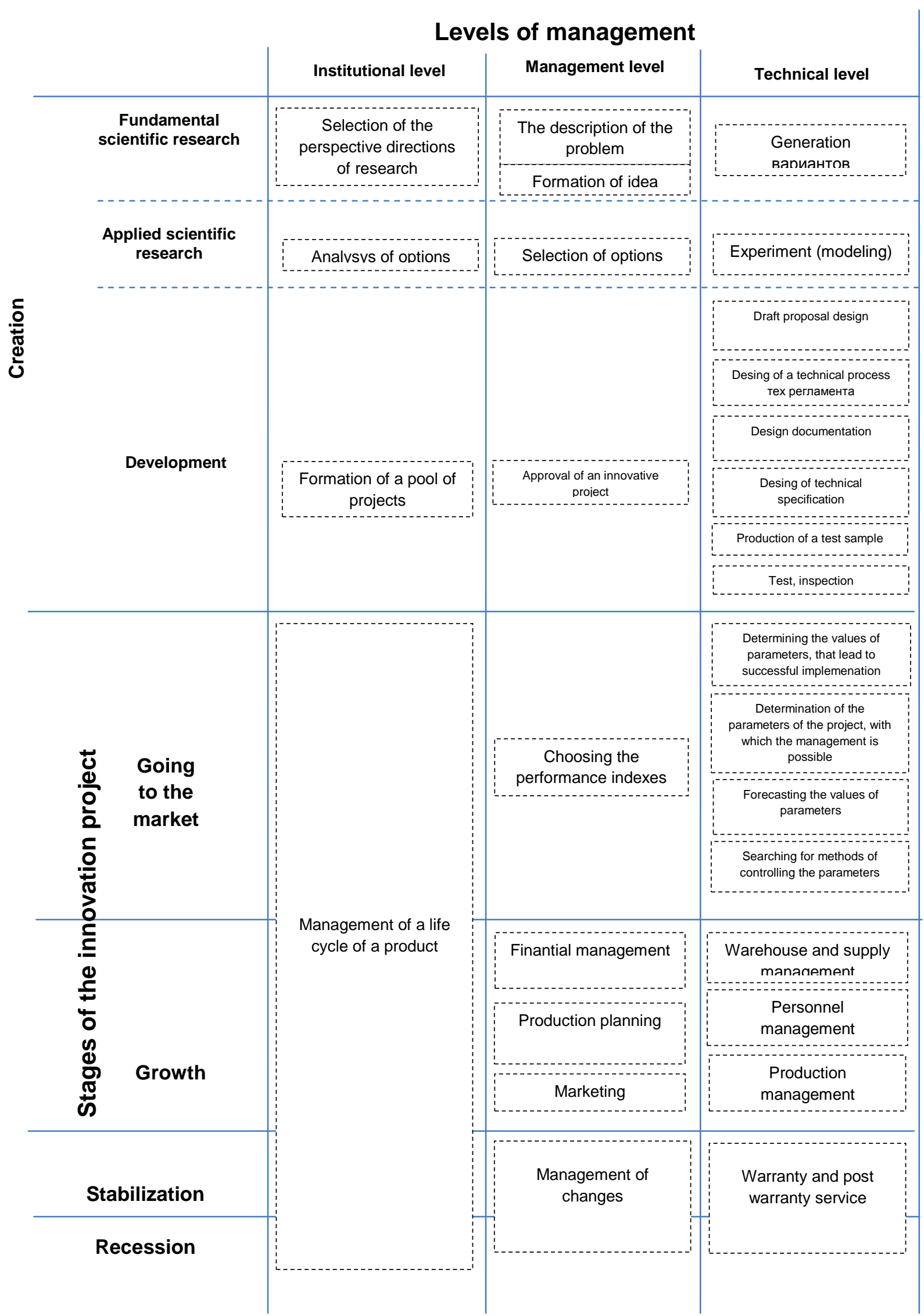

Fig. 2. Classification of problems solved by the implementation of innovative projects, depending on the stage and level of management [6] 
Any project, depending on the application area can be described by the set of parameters. This parameters can be divided into several groups:

- financial (income, credit, income from sales, deduct - charges on loans, salary, cost for implementation and modernization of production);

- technological (the parameters that describe the processes occurring in the workplace);

- technical / physical (product specification);

- other options (possibilities in terms of supply of components or materials, the wishes of consumers, etc.).

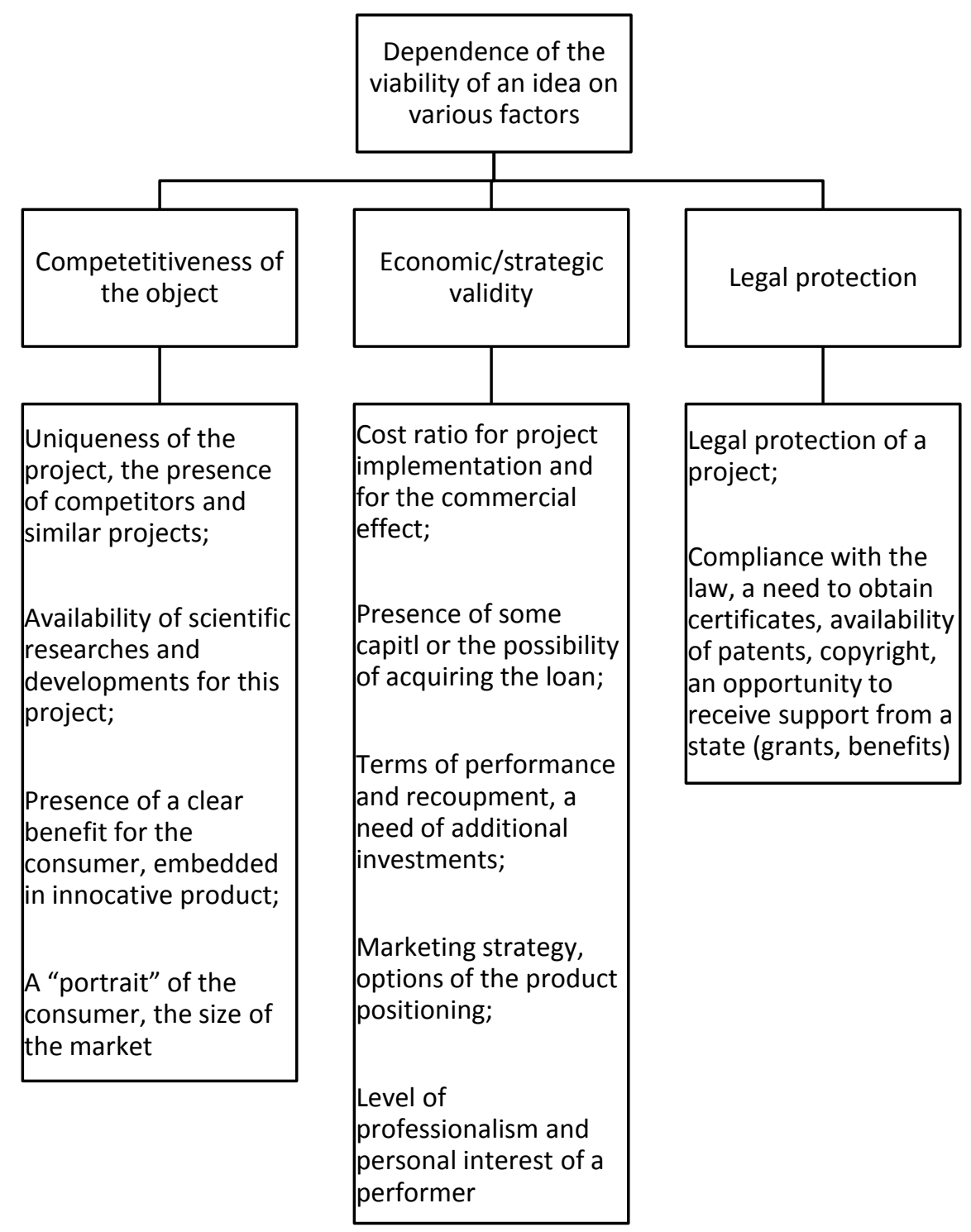

Fig. 3. Criteria for evaluation of innovative projects in selecting the concept for their implementation

In the process of project development, each parameter goes through a few steps of its development. Therefore, by selecting the most important (in the meaning of the final draft) parameters and by estimating the stage, on which each parameter is, we can estimate its growth potential and prospects of development of the project. If one can take into account the mutual influence of the parameters of the project, it will work out solutions that lead to progress on the set of parameters describing the project. Thus, the problem of generation of possible solutions is reduced to the problem of optimal search of groups of parameters' values of the project. 
Below, the unified curve of the development of an innovative project [1] by one of the parameters is shown.
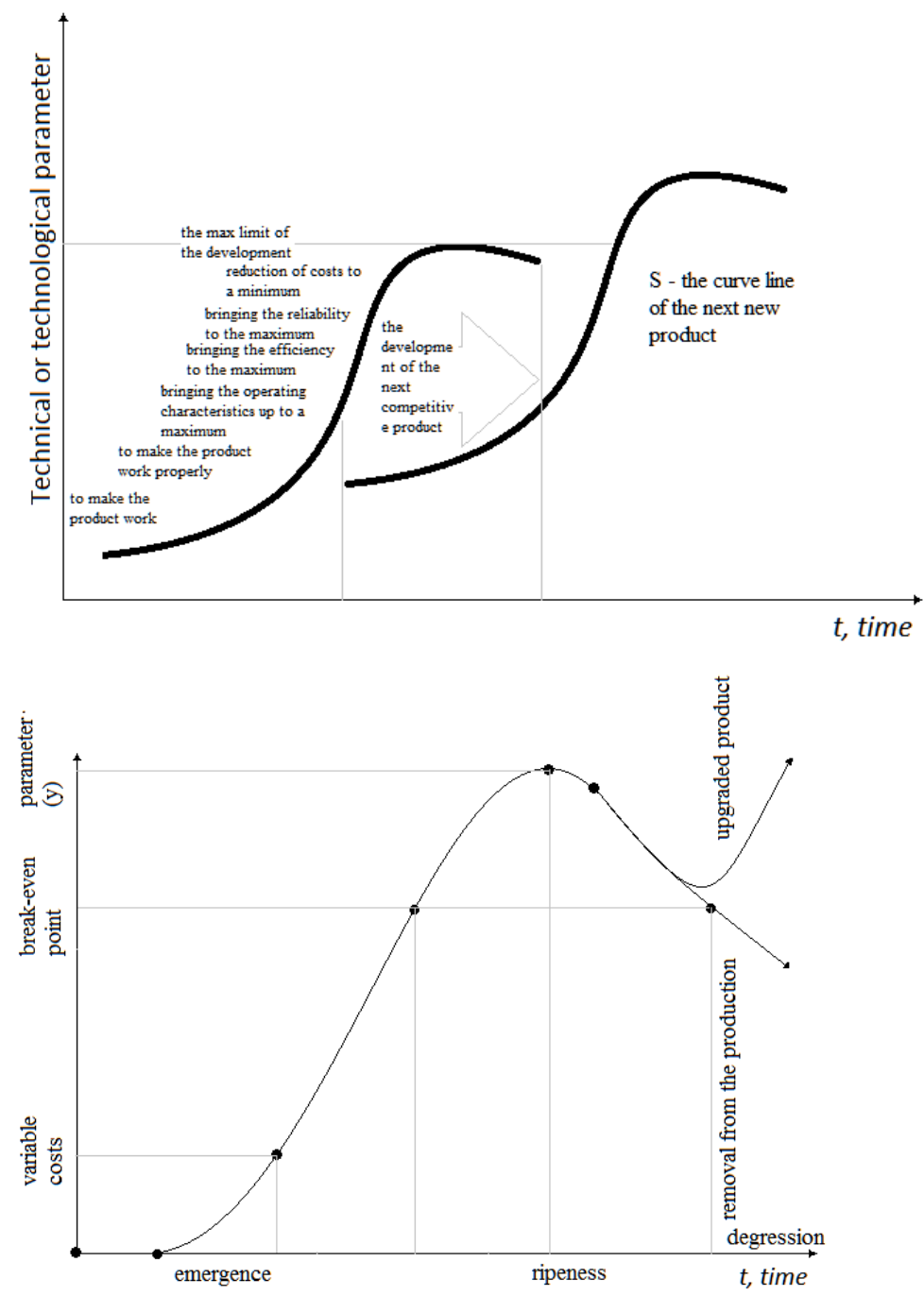

a)

b)

Fig. 4. The innovative curve: a) the transition from one project to another [3],

b) stages of the innovation project on innovation curve $[2,4]$

As we can see in Figure 4, on the curve, there can be distinguished four stages: the emergence of the idea, entering the product to market, growth, maturity and decline. This stages matches to the stages according to the ISO classification system, shown above.

In general, each innovative project is going through several stages of development, which are described either through innovation curve (economic parameters: income, sales, place in the market, which takes a firm or product, the number of competing products or firms, the number of people involved in work on the project, product quality, etc.), or by using an S-shaped curve (technical and technological parameters: the cost of developing or implementing of the new technology or process). This curve shows the level of technology development and prospects for its modernization. Each parameter of an innovative project may be on it's stage of development, and can be described by it's functional connection.

Thus, the problem of management of innovation projects is reduced to the problem of evaluation of the development potential for each of the options and making decisions that leads to progress on the set of parameters.

In order to consider the system as a project, one or more options that will pass through all the steps can be distinguished. Such indicators or parameters are determined depending on the purpose of the project (an effect that is expected to receive). 
Solving the problem of marketing. One of the problems which solution is required at all stages of the innovation project is the problem of marketing. However, the formulation of this problem differs depending on the stage. Thus, at the stages of scientific research and entering the market the main question is whether there will be a demand on goods in the market. At the stages of implementation, stabilization and decline the task of stimulating sales becomes the main problem. Despite the fact that this tasks are conceptually very similar, they may have different mathematical formalization.

1. Assessment of the prospects of product innovation.

In order to assess the prospects of the product, the market reaction to similar goods can be considered.

In order to take into account the preferences of customers, there exist methods based on surveys or expert assessments, but these estimates are subjective and can not take into account the subjective factors that influence the decision for an individual user (shop in which there are sales, product name, brand, etc...) All of these factors in combination may be considered only on the basis of statistics without isolating each factor in a separate assessment.

The accumulation of such statistics became possible with the advent of online shopping, where, on the basis of such information, the groups of goods displayed on the screen for a specific user are being formed. These techniques are now also being transferred into off-line sales.

Despite its apparent remoteness from the production, this approach allows to identify products that sell well together, to forecast their demand and on its basis to draw up plans for production volume of products and sets of products, that are useful to produce.

Lets analyze the data analysis process of buying goods in the online store. Suppose, the data contain information about the sequence numbers of sessions (which can be roughly considered as buyers), about purchased laid in the basket, and viewed goods. To solve the problem of selecting the closest (of interest) goods the principle of similarity of goods is being used, which is regarded as the similarity of the corresponding operations made with goods with respect to different users.

Thus, suppose that it is given the array of the form [Session Number | item number | type of operation], which is a text file consisting of rows of the specified type. Then the data set can be transformed into a matrix (Table 1).

Table 1: The statistical matrix of the actions of the buyer from the internet store

\begin{tabular}{|c|c|c|c|}
\hline № session & Item $1\left(\vec{T}_{1}\right)$ & Item $2\left(\vec{T}_{2}\right)$ & Item $3\left(\vec{T}_{3}\right)$ \\
\hline $\mathbf{1}$ & $a$ & $a$ & $c$ \\
\hline $\mathbf{2}$ & $a$ & $b$ & $a$ \\
\hline $\mathbf{3}$ & $b$ & $c$ & $c$ \\
\hline
\end{tabular}

In Table 1 coefficients a, b and c indicates: " $a$ " - items viewed, " $b$ " - items, which were putted in the basket, «c»- purchased items.

Numerically, the coefficients for each operation can be calculated as the ratio of the number of operations in the array corresponding to the number of operations on goods in the array.

Then, to determine the similarity we use the cosine of the angle between the vectors formed by the columns of values for each product (simplified representation of item-to-item algorithm) [5]:

$$
S=\cos \left(\vec{T}_{1}, \vec{T}_{2}\right)=\frac{\vec{T}_{1} \cdot \vec{T}_{2}}{\left|\vec{T}_{1}\right| *\left|\vec{T}_{2}\right|}
$$

where $\vec{T}_{i}$ vector (columns), corresponding to the goods.

On the basis of these calculations the table of commodities can be filled. The greatest numerical value of the cosine is between goods that are sold, or placed in the basket, or reviewed together most often.

It should be noted that similar items can be viewed as so-innovations. This products will fall into one or complementary groups of goods and have similar innovation curves. This allows us to 
combine this curves, consider a group of two products as one. Another possibility is to use data from the curves of similar products in the tasks of planning a new production.

So at the stage of entering the market we can have an idea of what will be our level of sales, thus defining for itself performance parameters.

\section{Stimulation of demand.}

At the stage of growth and stabilization we will consider the task of stimulating the demand. Here we can identify the most influencing (on the success of the project) parameters by estimating the percentage of sales, changes in demand over time, and so on. Let's consider this problem on the example of stimulating the demand for on-line store.

We evaluated a variety of arrangements and the probability of their success (ie, the probability of payment by the buyer of goods). Statistics was derived from a variety of different parameters, not all of which eventually actually influenced on the final result.

While developing the algorithm there were used the parameters with which the probability of non-payment was more than $10 \%$. The greatest probability of non-payment (31.94\%) is when the parameter «cookie» matches for the last 3 days. The other parameters were not displayed because they didn't have the sufficient impact on the final result and could give it only being aggregated (that could make the algorithm more complex. As a result we have a list of parameters, which cause the biggest influence on the systems behavior. So, by using them we can predict the possibility of how successful the sale will be.

Nowadays there are a lot of ways to analyze the gained statistics. Each of them provides the best accuracy in the special conditions of the problem. For example the problem can be solved by building the math model, based on fuzzy logic, neural network, mathematical regressions. In this case, we have a rather specific information, so we can use a fairly simple and therefore very accurate method of data analysis - the method of Naïve Bayes.

The point is to make the formation of rules for making decisions on the basis of several independent variables. The name Naive comes from the "naive" suggestion, that all variables are independent from each other. In the real life it is not always acceptable, but it can be applied for our problem.

The possibility of belonging of the object $i_{j}$ to the class $c_{r}\left(y=c_{r}\right)$ will be defined as $P\left(y=c_{r}\right)$.

The event corresponding to the equality of independent variables to certain values will be denoted as $E$, and the probability of its occurrence as $P(E)$. The idea of the algorithm is to calculate the conditional probability of belonging of the object to the $c_{r}$, when independent variables are equal to certain values. From the theory of probability it is known, that it can be calculated by the formula:

$$
P\left(y=c_{r} \mid E\right)=\frac{P\left(E \mid y=c_{r}\right) P\left(y=c_{r}\right)}{P(E)} .
$$

In other words, the rules are formed, in which all independent variables are compared with the corresponding possible values. The final part contains all the possible values of the dependent variable:

if

then

$$
x_{1}=c_{p}^{1} \text { and } x_{2}=c_{p}^{2} \text { and } \ldots x_{m}=c_{h}^{w} \text {, }
$$

$$
y=c_{r} .
$$

For each of these rules the probability is determined (Bayes formula). In order to calculate the probability of possibility of a given event, you should first compute all the conditional probabilities $P\left(E \mid y=c_{r}\right)$.

Examples of data analysis. But, in order to use this method, at first the data have to be analyzed. It has to be decided, which parameters it is necessary to take into account (which can influence on the final result), and which parameters are useless. In order to do that each parameter must be analyzed separately. A part of this analysis we can see below. 


\begin{tabular}{r|r|r|r}
\hline \hline Value & \multicolumn{1}{|c|}{ Proportion } & \multicolumn{1}{c|}{ count } \\
\hline ja & & 5,82 & $174 \mathrm{E}$ \\
\hline nein & & 94,18 & 28252
\end{tabular}

Fig. 5. A percentage of failed sales among all sales

The total number of non-payments - 1764 of 30,000 (5.82\%)

\begin{tabular}{|l|l|r|}
\hline TARGET_BETRUG & B_EMAIL & Record_Count \\
\hline ja & ja & 1153 \\
\hline ja & nein & 593 \\
\hline nein & nein & 5444 \\
\hline nein & ja & 22810 \\
\hline
\end{tabular}

Fig. 6. A percentage of failed sales when the field "e-mail" is not filled

As it is seen in the Fig.6.

If the field "e-mail" was filled, the possibility is $=1153 / 30000$

If the field "e-mail" wasn't filled, the possibility is $=593 / 30000$

The percentage of non-payment of all those who have "e-mail" - 5.05\%

The percentage of non-payment of all those who do not have "email" - 10.89

Considering it, we should first take into account the possibility of non-payment among those, who didn't fill the "e-mail” field.

\begin{tabular}{l|l|l|r}
\hline & TARGET_BETRUG & B_TELEFON & Record_Count \\
\hline 1 & ja & ja & 141 \\
\hline 2 & ja & nein & 1605 \\
\hline 3 & nein & ja & 4366 \\
\hline 4 & nein & nein & 23888
\end{tabular}

Fig. 7. The connection between sales success and a filled graph "telephone number of a customer"

As it is seen in the Fig. 7:

If there is a phone, then the probability is $141 / 30000$, if not, then it is $1605 / 30000$.

The percentage of non-payment among all those who have a telephone number - 3.23\%.

The percentage of non-payment among all those who do not have a phone number $-6.72 \%$.

As we can see, this parameter does not make a big influence on the result, so it may not be taken into the account.

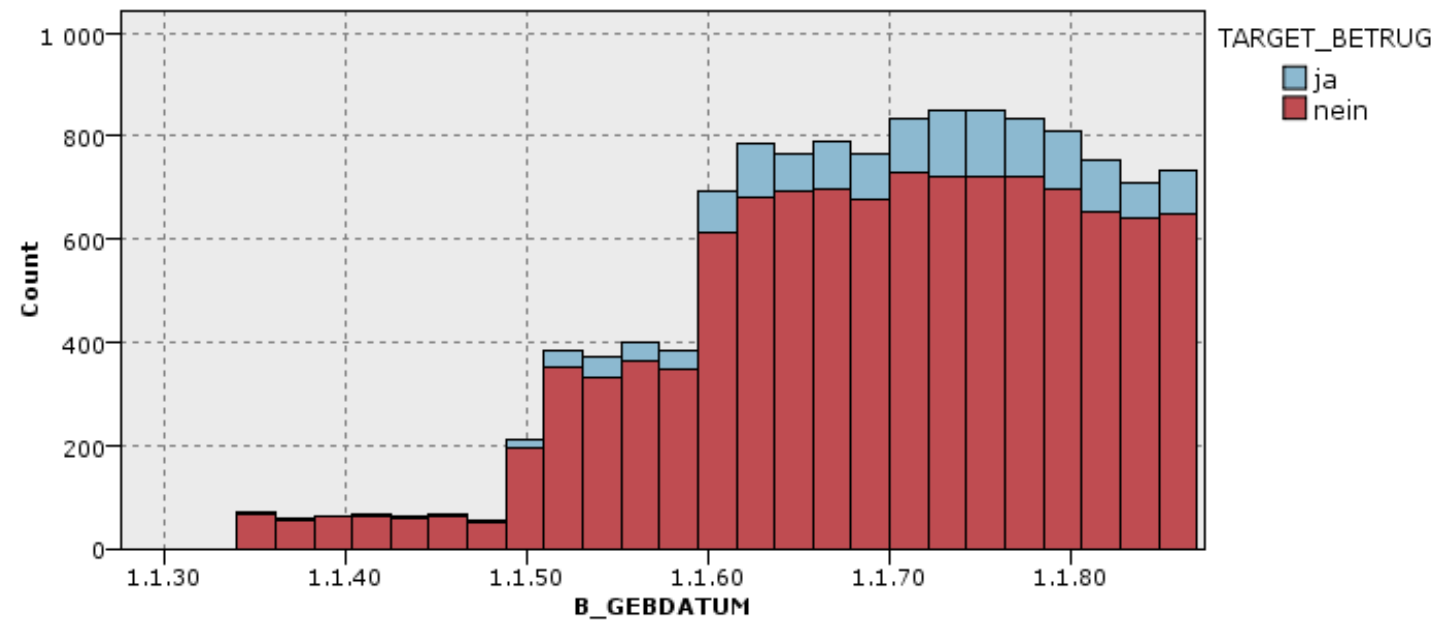

Fig. 8. The possibility of success in sales depending on the customers age 
Depending on the age of the customer.

If the customer's date of birth is less than 1950, then the probability of non-payment drops sharply. (At the same time the number of customers with the year of birth before 1950 in the total mass is small. The probability of non-payment increases significantly among those, who are 25-35 years old, ie born in 1970-1980. It reaches an average of $16.5 \%)$. So we may take to the account the customers with the age from $25-35$.
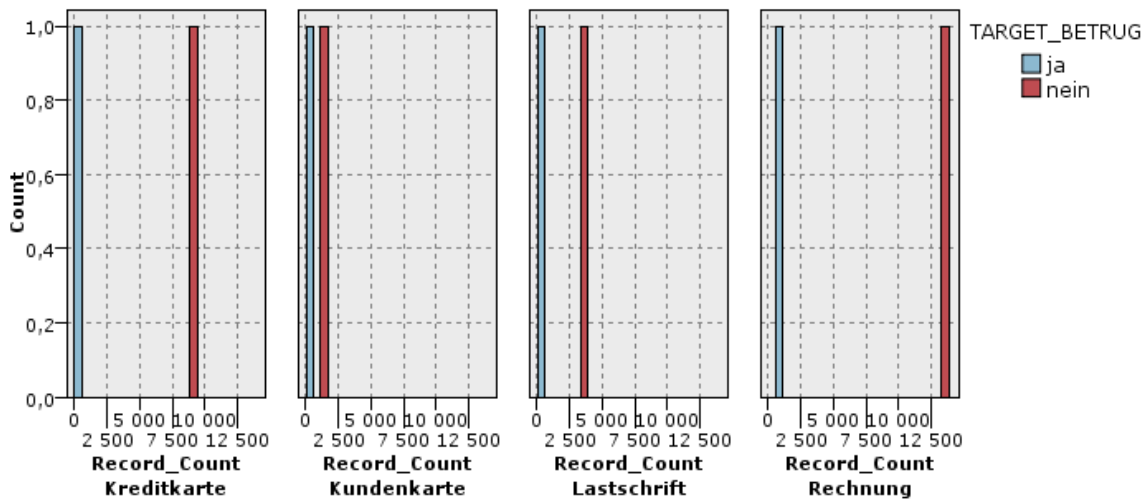

\begin{tabular}{|l|l|l|r|}
\hline & TARGET_BETRUG & Z_METHODE & Record_Count \\
\hline 1 & ja & Kundenkarte & 19 \\
\hline 2 & ja & Lastschrift & 223 \\
\hline 3 & nein & Kundenkarte & 1531 \\
\hline 4 & ja & Kreditkarte & 528 \\
\hline 5 & nein & Lastschrift & 3623 \\
\hline 6 & ja & Rechnung & 976 \\
\hline 7 & nein & Kreditkarte & 9268 \\
\hline 8 & nein & Rechnung & 13832 \\
\hline \hline
\end{tabular}

Fig. 9. Possibility of non-payment depending on the way, how it meant to be payed

When Kreditkarte (1) the probability $=9268 / 30000(5.69 \%)$.

When Kundenkarte (2) the probability $=19 / 30000(1.24 \%)$.

When Lastschrift (3) probability $=223 / 30000(6.16 \%)$.

When Rechnung (4) the probability $=976 / 30000$ (7.06\%). 

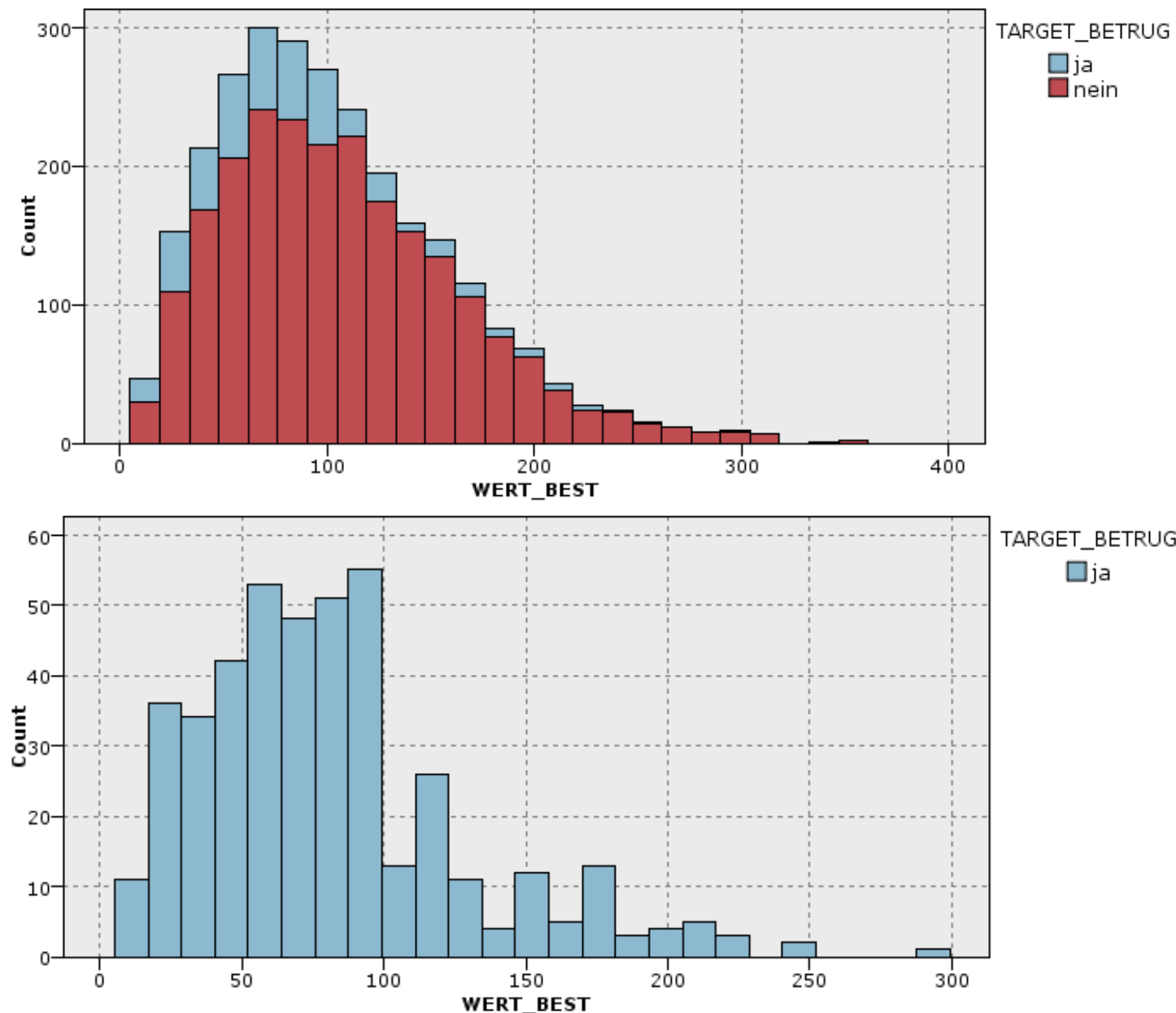

Fig. 1O. The possibility of non-payment, depending on the total cost of the order

The highest probability for non-payment when the total cost of an order is 93 euros, special attention should be given to goods which are in the price range of 20-100 euros).

\section{Conclusion}

As a result of this work, we can conclude that, considering the current marketing problem, as the problem of applying humanitarian ideas, it can be formalized and the possible solutions can be calculated with a high degree of reliability. This confirms the prospects of the chosen approach. Thus, in the course of further research detailing the problem of marketing of innovative projects and its formalization in the form of algorithm will be continued.

\section{References:}

1. Adizes, I. Corporate Lifecycles: how and why corporations grow and die and what to do about it. Englewood Cliffs, N.J. : Prentice Hall, 1988.

2. Amberg M., Mylnikov L. Innovation project lifecycle prolongation method // Innovation and knowledge management in twin track economies: challenges \& solutions. 2009. Vols 1-3. pp. 491-495.

3. Beelaerts Van Blokland W., Verhagen W., Santema S.C. The Effects of Co-Innovation on the Value-time Curve: A Quantitative Study on Product Level// Journal of Business Market Management. 2008., T. 2, 1.

4. Dietrich L., Schirra W. Innovationen durch IT (Erfolgsbeispiele aus der Praxis). Berlin : Springer-Verlag, 2006. p. 515.

5. Lemire, D., Maclachlan, A. Slope One Predictors for Online Rating-Based Collaborative Filtering. In: Proc. of SIAM Data Mining, 2005. 
6. Mylnikov L.A. A System View of the Problem of the Modeling and Control of Production Innovations // Scientific and Technical Information Processing, 2012, Vol. 39, No. 2, pp. 93-106.

7. Mylnikov L., Amberg M. The forecasting of innovation projects parameters //Vision 2020: Innovation, Development Sustainability, and Economic Growth - Proceedings of the 21st International Business Information Management Association Conference, IBIMA 2013, pp. 10171029.

8. Schumpeter J. Capitalism, Socialism and Democracy. Harper and Row: New York, 1942. 9. Voigt Kai-Ingo Industrielles Management.-Springer, 2008. - 695 p. 